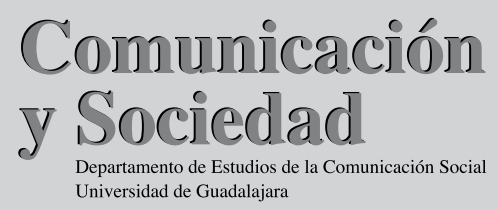

RESEÑA

\title{
Lazos familiares y redes de negocios. Biografía de Emilio Azcárraga Vidaurreta
}

FRANCISCO HERNÁNDEZ LOMELÍ*

\section{ANTECEDENTES}

La historia de la televisión mexicana va construyéndose poco a poco. Académicos formados en distintas disciplinas, así como periodistas, técnicos y locutores han puesto a consideración del público múltiples versiones sobre el origen y el desarrollo de este medio de comunicación,
Olivares Arriaga, María del Carmen

Emilio Azcárraga Vidaurreta. Bosquejo biográfico.

Ciudad Victoria:

Universidad Autónoma de Tamaulipas. Instituto de Investigaciones Históricas, 2002.

mismo que se estableció en México de manera regular y permanente en septiembre de 1950. Esfuerzos individuales e institucionales han fructificado en más de 20 obras, cuyo tema principal es, precisamente, el surgimiento de la televisión mexicana. Paradójicamente, los historiadores han contribuido muy poco en la conformación de esta historiografía; la gran excepción es sin duda la obra El Tigre Emilio Azcárraga y su imperio Televisa de Andrew Paxman y Claudia Fernández publicada en 2000.

* Universidad de Guadalajara.

Correo electrónico: franciscoh@csh.udg.mx 


\section{LA OBRA}

La Universidad Autónoma de Tamaulipas, a través de su Instituto de Investigaciones Históricas, tuvo el acierto de encomendar a la historiadora María del Carmen Olivares Arriaga y a su equipo de colaboradores hacer una biografía de Emilio Azcárraga Vidaurreta (EAV). Con este encargo se buscó "rescatar y destacar las aportaciones" (p.5) de este empresario del audiovisual, nacido en Tampico, Tamaulipas, el 2 de marzo de 1895. EAV fundó en 1930 la estación radiofónica XEW; a partir de 1946 participó en la industria de la cinematografía como productor y exhibidor, y en 1952 puso en marcha el Canal 2. Fue artífice de Telesistema Mexicano, empresa que monopolizó la televisión comercial mexicana de 1955 a 1972, y que fue antecedente inmediato de Televisa. Presidió organizaciones nacionales e internacionales, como la Cámara de la Industria Radiofónica en México y la Asociación Interamericana de Radiodifusión. Un personaje de esta densidad bien merece un estudio biográfico.

El resultado fue una obra de 212 páginas, urdidas con la información de fuentes primarias provenientes de archivos y hemerotecas. La autora entrevistó a 13 personajes que tuvieron relación con EAV y realizó una revisión bibliográfica. La obra está generosamente ilustrada con más de 40 fotografías, 16 documentos facsimilares, casi media centena de cuadros que ordenan e indican las referencias y ubicación de los documentos consultados.

\section{LOS APORTES}

Las contribuciones más importantes de Emilio Azcárraga Vidaurreta. Bosquejo biográfico son, sin lugar a dudas, la minuciosa reconstrucción del ambiente totalmente favorable a los negocios y el papel desempeñado por las redes familiares en la consolidación de las iniciativas empresariales de EAV. Estos aportes fueron posibles gracias al detallado trabajo de archivo realizado por María del Carmen Olivares.

La historia de esta familia inicia en 1830 con el establecimiento en el puerto de Tampico de Mariano Azcárraga Peña. Para 1839 era ya "síndico primero y posteriormente tesorero municipal o recaudador y 
depositario de los derechos municipales. Don Mariano logra desplegar gran actividad social y formar un fuerte capital" (p.118). De su matrimonio con Albina Ramos nació Francisco Marcial Azcárraga, este entró a trabajar en el servicio aduanal y "llegó a ser alcalde de la aduana marítima del puerto de Tampico, empleo que desempeñó desde 1884 hasta su fallecimiento acaecido en 1891" (idem). Del matrimonio de Francisco Azcárraga Ramos y Julia López de Rivera nació Mariano Azcárraga López de Rivera, quien se desempeñó como escribiente, y posteriormente contador de la aduana marítima de Tampico. Fue trasladado a la aduana de Piedras Negras, y a principios del siglo XX, don Mariano fue administrador de la aduanas fronterizas de Nogales y Nuevo Laredo, y también de la aduana marítima de Veracruz. De su matrimonio con Emilia Vidaurreta nació Emilio Azcárraga Vidaurreta.

Todos estos antecedentes son importantes porque demuestran que el patrimonio de la familia Azcárraga venía acumulándose a lo largo de los años. La autora demuestra que el bisabuelo de EAV era un hombre rico. Durante tres generaciones, la vida familiar estuvo vinculada a las actividades aduanales y a los negocios privados de bienes y raíces. Fueron gente respetada y con arraigo en la región nororiente de México.

La investigación pone de manifiesto que EAV estuvo familiarizado con la cultura estadounidense y su forma de hacer negocios. En efecto, realizó estudios en St. Edwars College, en Austin, Texas. La región norte de México experimentó a principios del siglo XX una bonanza económica. La interconexión de las redes ferroviarias nacionales, y con las de Estados Unidos, el inicio del proceso de industrialización de la ciudad de Monterrey y la importancia del puerto de Tampico como lugar estratégico de la industria petrolera establecida en México, generaron una intensa actividad de negocios. EAV supo aprovechar este dinamismo económico.

Las redes familiares es el otro ingrediente de la consolidación empresarial. En los negocios de EAV siempre aparecían como socios algún hermano, cuñado o su propia madre. Estas redes de parentesco se ampliaron cuando EAV contrae matrimonio con Laura Milmo, hija del inglés Patricio Milmo, nieto de James F. Milmo, accionista mayoritario del Milmo National Bank of Laredo. La familia Milmo poseía inversiones en industrias ubicadas en los estados de Nuevo León, Coahuila, Durango y Tamaulipas. 
Con esta historia a cuestas, EAV y sus hermanos Gastón y Rogerio iniciaron en 1917 la compra de automóviles Ford procedentes de Estados Unidos, con la idea de venderlos a crédito en México. Para el año siguiente los hermanos Azcárraga se asocian con un estadounidense para fundar la empresa "Azcárraga y Copeland", con el objeto de "vender automóviles Ford y accesorios de automóviles" (p.149).

La incursión en la industria del entretenimiento inició en 1922, cuando EAV participa en la creación de la empresa "The Mexican Music Company, S.A.", que tenía como objetivo "el establecimiento $\mathrm{y}$ explotación mercantil en el ramo de música y en todas sus manifestaciones; en la compra, venta y manufactura de toda clase de instrumentos musicales, edición o compra y venta de música impresa, y en general todos los demás artículos del ramo..." (p. 125). En junio de 1930, EAV fundó en Monterrey la estación radiofónica XET, y tres meses después inauguró en la ciudad de México la estación XEW (p. 123). Desde entonces la radiodifusión mexicana adquirió características industriales.

\section{LIMITACIONES}

La queja principal que hay que hacerle a la obra Emilio Azcárraga Vidaurreta. Bosquejo biográfico es que el rigor, acuciosidad y profundidad que la autora aplicó para reconstruir el clima empresarial favorable que prevaleció en el norte a principios del siglo XX, y para recuperar las redes de negocios de la familia Azcárraga, no se aplicó con la misma intensidad en el análisis de las actividades empresariales de EAV ocurridas después de la fundación de la XEW. María del Carmen Olivares Arriaga utilizó fuentes primarias para la reconstrucción de la historia de los Azcárraga hasta 1930, y a partir de ese año se apoya en entrevistas y en un recuento bibliográfico que no es exhaustivo. Por ejemplo, se menciona muy poco las actividades de EAV en la industria cinematográfica y la industria hotelera. Es cierto que dedica espacio a la creación del Canal 2 de televisión, sin embargo no se reflexiona sobre la creación del monopolio Telesistema Mexicano. No nos cuenta tampoco cómo fue la relación que Emilio sostuvo con otros empresarios que competían con él. 
No es que la historia después de 1930 sea mala; de ninguna manera, sólo que el periodo anterior fue trabajado de mejor forma. No obstante, la obra que aquí se reseña es indispensable para entender una parte de la historia de la radio y la televisión en México. 